\title{
Sociological Discipline and the Unruly Erotic
}

\author{
Agnes Bolsø \\ Department of Interdisciplinary Studies \\ Norwegian University of Science and Technology \\ 7491 Trondheim, Norway \\ Tel: 47-73-591-727 E-mail: agnes.bolso@ntnu.no
}

Received: December 26, 2011

Accepted: January 27, $2012 \quad$ Published: March 1, 2012

doi:10.5539/res.v4n1p94

URL: http://dx.doi.org/10.5539/res.v4n1p94

The research is financed by The Norwegian Research Council and The Norwegian University of Science and Technology.

\begin{abstract}
Will sociological theory and methodology, with its inclination towards ordering and structuring of the social, ever manage to come to grips with sexuality and the vicissitudes of fantasy, desire and passion? There is no clear answer to the question, and sociologists engage theoretically and empirically in a number of ways in studies of the sexual, often looking to other disciplines for perspectives to inform the analysis. In this paper, theoretical concepts from psychoanalysis are deployed in an attempt to deconstruct the conceptual distinction between homosexual and heterosexual practices. The author introduces a notion of 'triangulation', drawn from psychoanalysis, where a third eroticising element is seen as part of the relation between desiring individuals, thereby making the distinction between 'homosexual' and 'heterosexual' a more problematic one.
\end{abstract}

Keywords: Desire, Sexuality, Deconstruction, Psychoanalysis, Queer theory, Sociological theory

\section{Introduction}

For just three-four decades now, western sociology has come a long way in theorising sexuality. From, as the American sociologist Steven Seidman puts it, viewing 'sexuality as part of nature' to fashioning a variety of frameworks to analyse it (Seidman 1996:1-2). The second half of the 1960's saw central works of American scholars like William Simon and John Gagnon, suggesting sociological perspectives on sexuality. In Britain Mary McIntosh published her groundbreaking article 'The homosexual role' while The House of Commons where debating the law against homosexual behaviour. This was in 1968 and the main argument for a de-criminalization was that the homosexual was sick and therefore not a criminal. McIntosh was much in disagreement with such an argument, but found it problematic to talk about it in the British public where it was applied in favour of homosexuals. She eventually chose to publish her article in an American journal. 'There wasn't such a hopeful movement for law reform in America at the time. But there is also the fact that I would not have known what journal to publish it in in this country', she later explained in an interview with British sociologists Jeffrey Weeks and Kenneth Plummer (Plummer ed 1981:45). This has certainly changed. Well into the 1970's the studies of sexuality as a matter of the social had caught its momentum, and we have seen a major development in the field of sociological sexuality studies from then on, in Britain as well as in other Western countries.

Unsurprisingly, sociologists first of all grappled with the social and cultural aspects of sexuality, and how the desires and longings of the individual are interwoven with people's diverse external contexts and lived practices. Sociology belongs after all to social science. It happens, however, that sociologists have also made attempts to take on board perspectives from psychology and psychoanalysis, in the pursuit of a more thorough understanding of erotic desire 'itself'. This is of course risky business for those trained in sociology, since at least the understanding of social structures and perhaps also a general sociological awareness tends to falter when desire becomes the main object of study. And also, one can hardly expect full recognition from other scholars who do philosophical or 
clinically-based psychoanalytical analysis. So, it is only with a certain nervousness that in this article I join with other fellow sociologists who have applied psychoanalytical theory in their sociological analysis of erotic desire.

Our erotic experiences are complex and varied, and we often have all too few linguistic resources when we talk and write about them. In particular, the conceptual binary heterosexual-homosexual marshals any discussion in specific ways, as if inviting us to try to keep untidy confusions in order. Some oppose this prescribed order by claiming 'bi', 'queer', 'metro', or other hybrid or new identities. However, it is highly debatable whether any of these concepts actually escapes some notion of heterosexual normality as a given premise for its meaning, as the word 'sexuality' itself first of all conjures up two sexes involved in traditional reproduction. I would like this article to be read as an attempt to deconstruct sexual identity categories further. The aim is to explore erotic desire while keeping in check the urge to label different forms of desire, by applying an analytical model that is relatively disconnected from the main dichotomy heterosexual-homosexual. The model is applied on interviews with young adults. Another purpose with the article is to reflect on ways for sociologists to incorporate ideas from psychoanalysis in the pursuit of a deeper understanding of erotic desire.

Sexual/erotic (Note 1) desire is central to any sexual identity. A challenge for sociology, as in fact it is for any other academic discipline, is the embeddedness of desire in fantasy and in the unconscious. It follows that it is very difficult to get information about desire outside (and even inside) of a therapeutic situation. I'll first take a look at works of some sociologists in the field of erotic desire and position my own work in relation to them, before I continue with an account of my own analytical enterprise.

\section{Sociology and Sexual Desire - a Brief Account}

From the founder of psychoanalysis Sigmund Freud's own work, to that of Wilhelm Reich, Herbert Marcuse, Theodore W. Adorno, George H. Mead, Kurt Lewin and others, social science has seen several interdisciplinary streams emerge, with labels such as 'psychosocial studies', 'psycho-sociology', 'socioanalysis' and 'sociopsycho-analysis'. ISA, The International Sociological Association has 53 research committees, of which one is 'social psychology' and another 'clinical sociology', bearing witness to the 'legitimacy' of the sociological exchange with psychology and psychoanalysis (http://www.isa-sociology.org/). The link to psychoanalysis often goes via the strand of 'object-relations theory', probably because the theoretical centrality of 'other(s)' in the development of the individual self, offers promising insights for the sociologist. The perhaps most influential sociologist working with psychoanalytical theory of sexual desire, Nancy Chodorow, formulates object-relation theory like this:

'Object-relation theorists, emerging from and reacting to the work of Melanie Klein, image a course of transactions between self and other(s) that help form our first subjectivity and sense of self, and that throughout life are renegotiated to recreate the sense of self and others in term of connection, separation and in between. These transactions give depth and richness of meaning to experience, by resonating with the past and with constructions of the past' (Chodorow 1989:10).

Here, Chodorow emphasises not only how the individual depends on others in the formation of subjectivity, but also the dynamic aspect and the ever lasting continuity of ones exchanges with others. Writing over a substantial period of time, from the early 1970's, through the feminist heydays and onward up till now, Chodorows understanding of gender and sexuality has undergone shifts. I 1994 the British psychologist and feminist Lynne Segal was summing up a critique of the early Nancy Chodorow for "narrowing down the conflicts and complexities of both the psychic and the social world, and ignoring differences between as well as within women - or men - in conformity with existing gender stereotypes (Segal 1994:143). Nancy Chodorow's former student, now professor in sociology, Steven Epstein conveys an aspect of this critique in his well known essay 'Sexuality and identity: The contribution of object relations to a constructionist sociology' (1991). The essay represents a near 50 pages account for, and discussion and promotion of the possible gains from applying psychoanalytic theory, and object-relations theory in particular. He calls for an object-relations theory that can encompass not only the love and sex between men and women, but also the relations between men and between women. Epstein makes the point that sociology has managed to locate sexuality and sexual categories within its specific social and historical contexts, but needs to incorporate psychoanalysis to understand 'how people actively integrate feelings and experiences into more or less coherent wholes' (Epstein 1991:862). Epstein is in his essay grateful to Nancy Chodorow, his teacher, for her help with several drafts of the essay.

This is at a time when Chodorow herself has become 'consonant with modern, more decentered, views of theory', and 'views of the multiplicities of gender(ed) experience' (Chodorow 1989:7). Indeed, in 1994 Chodorow thanks her insightful and sophisticated students for this reorientation, Steven Epstein among them, in the book Femininities, Masculinities, Sexualities (Note 2). In the book Chodorow directly addresses sexuality and rewrites 
some of her former ideas. Of special interest to me here, is the chapter 'Heterosexuality as a Compromise Formation', where she argues that heterosexuality is problematic and has to be accounted for, as any other sexuality. She asks:

'How do we reconcile a complex and varied view of the multiplicity of sexualities and the problematic nature of conceptions of normality and abnormality with a dichotomous, un-reflected -upon, traditional view of gender and gender role, or an appeal to an undefined 'masculinity' and 'femininity'? '(Chodorow 1994:60).

How to talk about different forms of sexual desire, when genders and sexualities apparently had multiplied and both academics and activists had started to talk about the plurality of 'masculinity' and 'femininity'? I will reformulate this question further, when I later carry out my own empirical analysis.

If we again take a look at Chodorow's definition of object-relation theory above, it becomes clear that there is no big step between this and a broad range of perspectives applied within sociology when the aim is to grasp the exchanges between the macros and micros of people's lives. One example could be 'symbolic interactionism', as developed from the sociologists and philosophers George Herbert Mead and Charles Cooly, followed by Herbert Blumer as an eager proponent (Note 3). It is with George Herbert Mead's ideas on the development of selfhood, by 'taking the role of the other' (Mead 2005:188 [1934]), that Epstein (1991) suggests to start the integration of sociology and object-relation theory, but without being particularly concrete about how to do it. Another example could be Pierre Bordieu's notion of 'embodiment' and the corresponding concept of 'habitus', which is where the Canadian sociologist Adam Isaiah Green looks for a bridging between psychoanalytic theory and sociology.

Green agrees with Epstein (1991) that there has been a lack of attention from sociology on the 'structuring of sexual desires'. Moreover, seventeen years after Epstein's essay, Green says that the state of the field 'is arguably little improved' (2008:598). Green does not, however, directly follow up on Epstein's cue on the importance of 'the other' for the self. He develops a slightly different theoretical approach in an attempt to complement, with psychoanalytical perspectives, scripting theory and a sociology of sexuality that is limited to 'an insulated analysis of interactions and institutions' (2008:597). Green carefully accounts for Simon and Gagnon's (1986) and Laumann and Gagnon's (1995) 'scripting theory', the highly influential ideas about processes wherein the individual negotiates culture, and forms relatively stable ways of being sexually active. Scripting theory has a tripartite structure, as one addresses cultural scenarios, interpersonal scripts and intrapsychic scripts. This is not to be confused with my notion of 'triangulation of desire' below. Scripting theory aims at understanding people's sexual behaviour in a broad social and cultural sense. My aim in the following analysis is to understand erotic desire 'itself', and 'triangulation' is a quite narrow lens for understanding how individuals actually take erotic interest in others in specific situations.

Green's contribution to concrete empirical analysis is to re-analyse interview quotes from published works of other scholars. David Knapp Whittier and Rita M. Melendez' article 'Intersubjectivity in the intrapsychic scripting of gay men' (2004) points to the lack of complexity with which scripting theory is used: 'Characterizing sexuality as handed down in sets of scripts or cultural instructions for individuals to follow does not do justice to the complexities involved in sexual scripting' (Whittier and Melendez 2004:132). They suggest more emphasize on people's agency and aim to 'identify some of the social processes in intrapsychic sexual scripting' by presenting intersubjectivity, 'what individuals thought others thought of them, as a common process these men engaged in when thinking about their sexuality or their intrapsychic sexual scripting' (op.cit:133). I am sympathetic to their project, but will have to question the conceptual tools. If the concepts are to be thought of as psychoanalytical theoretical concepts, one could ask whether 'what I think others think about me' is a precise definition of intersubjectivity, and whether it is possible to have conscious access to ones intrapsychic scripting. However, I will not develop my own critique of Whittier and Melendez conceptual framework, as it is Green's reanalysis of their material that interests me here. I am indeed in agreement with him that the authors need a 'concept that captures the ways in which social structure is transformed into a psychological phenomenon in the form of enduring schemes of perception, dispositions, and inclinations' (Green 2008:621). Green establishes 'erotic habitus' as the sociological component of sexual desire that 'straddles social structure and unconscious processes' (op.cit:622).

When Green activates Bourdieu to complement scripting theory it is with a less all-encompassing interest than seems to be the case of Simon, Laumann and Gagnon. Green states that '..sexual desire will never be entirely accounted for or predicted by sociological explanation' (2008:623). However, he encourages us, as sociologists, to enter '(..) the forbidden netherworld of the psyche-society interface (..)' (op.cit:623). I follow Green both on his view on the limitations of sociology and in encouraging sociologist to find theoretical inspiration outside the boarders of the sociological discipline. The unconscious is crucial for both the fantasmatic aspect of sexuality and for 'transforming social structures into psychological phenomenon'. We have to be aware though, as Adam Isaiah 
Green seems to be, that sociologists are neither trained in accessing the unconscious parts of people's minds nor in analysing it.

I came to sexuality studies, not from sociological theorising as briefly sketched out above, but from gender studies and encounters with the philosopher Judith Butler and historian/philosopher/sociologist Michel Foucault, quite close to what Steven Epstein says in his contribution to the anthology Queer Theory/Soociology that some of us do 'directly from the work of Foucault, bypassing the social sciences entirely' (Epstein 1996:152) (Note 4). Informed by what one could call 'poststructuralist theory'/'queer theory' my research interests became deconstruction of concepts and deconstruction of the sociality and the politics of the erotic and of the sexual. My academic interest in sexuality has been, and still is, as much for the 'what might be', as for 'what is', and I came to object-relation theory, not via the sociologist/therapist Nancy Chodorow directly, as did my colleagues mentioned earlier, but via the philosopher Judith Butler and her discussion of the work of another object-relation theorist; Jessica Benjamin. There is a potential for mutual exchange between Green's work and mine, because it might be that my approach raises the awareness of possible shifts in the erotic habitus of the informant. A theoretical and conceptual reworking in that direction has to be explored at a later occasion.

My analytical model is a model for analysing the dynamic of the erotic desire within an interpersonal context. This is not to say that culture and society is not represented in the following analysis, but the model does not grapple with the socially interwovenness and effects of macro level antecedents on desire. This does not leave culture and society behind, but opens up for an analysis of erotic agency that is relatively free in certain moments of attraction and passion.

\section{Desire: Me, You and What Else}

I understand sexual pleasure as experiences that are seated in the body in particular modes. It not only sits in the body, like all human experience and cognition, but also is from the beginning conceived and understood first and foremost via and with the body. The effect of the experience of pleasure is a deep human longing, conscious or unconscious, for repetition. Yet, no one experience of pleasure can be exactly replicated. We can, however, continue to try the impossible by transferring our longings and wishes into new and other situations. I consider this to be central in the formation of the psychological structures of the subject's desire. In keeping with Freud's notion of the sexual object, I regard desire as a longing for something outside oneself, be it another person, a thing, or some aspect of one's own ego projected into another person (Freud 1977). This serves to anchor desire within pleasure, and in the searching for that what gave us pleasure and potentially might do it again. The desire of the subject is also for the desire of the other; the subject holds the fantasy of being an object. This makes us both subject and object in the very same relation of desire, which always makes desire too complicated to fully know.

Desire can, for the subject, get connected to different types of objects; particular persons, situations or things (fortunately, only a tiny minority lusts for all and everyone). Certain signifiers (erotic symbols, signs) mediate the connection between subject and object. The signs and symbols that count for the individual will vary. However, masculinity and the phallic are perceived as the hegemonic erotic signifiers in our culture (de Lauretis 1994). And even as Judith Butler deconstructs and reworks the notion of the phallic, turning it into a term that is more ambiguous, she also ascribes phallic eroticity to the lesbian relation in her critique and rewriting of Freud and Lacan in 'The Lesbian Phallus' (1993).

This appears to be ambiguous, since the phallus obviously is astray when it informs the erotic in a women-only relation. There is, however, not much ambivalence in this way of imagining the effect of the phallic; the phallic in psychoanalytic framings is the third element in the relation between the (most often) two participants (in the first instance, mother and child), and the phallic is that which enables sexual difference to be installed and erotic communication to happen. In 'The Lebian Phallus' Judith Butler reworks the Lacanian symbolic, and opens it up for possible changes via a 'critical release of alternative imaginary schemas for constituting sites of erotogenic pleasure' (Butler 1993:91). The Lacanian phallic third (The Law of the Father) is not allowed to maintain its position as the only erotic signifier. She reflects further on this in a later book Undoing gender (2004), in the chapter 'Longing for Recognition'.

The chapter represents a critique of contemporary psychoanalyst Jessica Benjamin and her suggested 'third'. In her later work Jessica Benjamin suggests that communicative speech, establishing a space for dialogue, could represent the third (Benjamin 1998:28). For Benjamin, Butler says, the third comes in as 'the intersubjective process itself' (Butler 2004:140), and it becomes valuable and ethical to search for a final and harmonic solution of the process. Doesn't Benjamin's harmonic third exclude the other possible thirds, the 'negative' ones?, Butler asks; 'The child who interrupts the encounter, the former lover on the door or on the phone, the past that cannot be reversed, the future that cannot be contained, the unconscious itself as it rides the emergence of unanticipated 
circumstance?' (Butler 2004:145-146). A main question for Butler in her critique is whether recognition free of misrecognition is possible. Is it true, asks Butler, that recognition can leave destructiveness behind? Butler engages in a generic and quite complex discussion on subject formation in this text, which is not within the scope of my article. It influences my analysis, however, that her concrete analytical examples are on the coconstitutive character of homosexuality and heterosexuality, which is said to offer a 'queer approach to triangularity' (Butler 2000:271).

Benjamin's non-Phallic third is not problematic enough for Butler, who wants something 'less jubilant' (Butler 2004:135). She finds Benjamin a little too optimistic regarding the possible harmony that Benjamin's notion of a third may provide. I agree with Butler that the negative and destructive is always lurking in the shadows, and also often disturbingly present (a previously held assumption, which Benjamin seems to have left behind, says Butler). I nevertheless find that Benjamin's harmony could be seen as a temporary one, and I will not always point to the possible other formative and potentially disturbing 'thirds', that would, in a study of a process of subject formation, be crucial to understand. I will here, quite brassily, pick up some elements from Butler's critique of Benjamin, as well as Benjamin's notion of the third, and apply these views and perspectives my own way. I alone must answer for my specific understanding and appropriation of the theory.

\section{Concepts and Analytical Approach}

I would like to approach my informant's stories in a way that encourages a rethinking of what hetero, homo- and bisexual desire might be. Both Butler's and Benjamin's form of thinking triangulation, provide a facilitating element outside the (often two) partners, that possibly can enable an expansion of the wording of the erotic going on between the partners. I will still use concepts such as man, woman, masculine, feminine, hetero, homo, but they will be put to work in a way that allows me to deconstruct understandings of the homo erotic and the hetero erotic. I will give a rough outline of some of the concepts that are used in the discussion to follow.

\subsection{Sexual subject - sexual object}

The sexual subject in my text is the one who occupies the position of speaker, i.e. the place from where the experience is told, in any particular discussion of the material. Usually this will be the informant, but it might also happen that the informant becomes the object in his own story. The sexual object, here, is the one (or the what) that the subject desires, as they are positioned in the interview.

\subsection{The subject, the object and the third}

Let us say that we see the narrative provided from the position of the subject. The subject desires an object (an 'other' with a small 'o'). However, this can never be completely straight forward, since the Other (i.e. the generalised object, or the fantasy of what the object might be) already is part of the desiring subject. I will here operate with a rather simple version of the Other, and only in the context of sexual desire and arousal. That it is connected to arousal is important, because this bodily experience is what links desire to something that it is possible for me to talk about with the informants, and possible for the informants to (consciously) describe. I will nevertheless carefully try not to let the meaning of desire collapse into that of sexual arousal. The Other (the generalised object) is a third, '..who (or which) engages, motivates, and exceeds a relation of desire at the same time that it constitutes it essentially', as Butler says about Benjamin's understanding of the third (2004:135). For Butler this represents an ideal of a process of transcendence in Benjamin's thinking that Butler cannot subscribe to. Counter to me, who in the present context of looking for a perspective to read interviews with, finds useful this way of understanding a third element in a relation of desire. So, I'll use the Benjaminian harmonizing third, but bear in mind Butler's critical points about the always returning other thirds, which will encourage me to question what seems to be a simple 'third'. A graphic illustration of the model:

subject - object

the third

The third eroticises the relation between the desiring subject and the object, in other words: the third represents the framing and constituting of it as an erotic relation.

\subsection{Eroticism and triangulation}

Eroticism is in this paper seen as equivalent to symbols and signs linked to sexual desire, that which makes sexual desire recognisable as such within a given cultural context. The third element for the individual is most often, but not always, a culturally familiar symbolic erotic entity, one that for the subject can represent the desirability of 
another person. The third element does not stay the same for the individual, but will vary from one relation to another, and change over time.

\subsection{The self}

The self is for both Butler and Benjamin unrelentingly bound to the Other, having come into existence only via the recognition by the Other. Drawing upon Hegel's notion of subjectification (Note 5), Butler claims that we possess power to misrecognise the Other, thereby to negate the existence of him. This means that the self also is always risking something, and here lies some of Butler's critique of Benjamin, who according to Butler seems to allow this risk to disappear.

\subsection{Triangulation without the father}

Must the third element and the mediator of desire always be phallic, since this sign is the most prominent erotic sign, with a nearly universal character? Butler and Benjamin both see other possibilities. For Benjamin there exists a site of dialogue creating the third, 'something like the dance that is distinct from the dancers yet cocreated by them' (Benjamin 1998:28 fn5), or as Benjamin said in talk in 1998: 'a site of mediation, the music of the third to which both attune' (Butler 2004:135, quoting Benjamin). As mentioned already, this is a bit too easy for Butler, who advocates the view that the dyad will always be threatened and that harmony has rejection, negation and aggression as always immanent within it and as constituting elements. Not only is 'the self already positioned outside itself', but who we fundamentally 'are' is also 'a subject in a temporal chain of desire that only occasionally and provisionally assumes the form of a dyad' (op.cit:151). This is counter to Benjamin's harmonic triangulation (the dyad at peace with itself), and also in contrast to any simple way of understanding sexuality and gender within the framework of the oedipal drama (thinking in terms of displacement allows 'triangulating echoes' within various forms of desire) (Note 6).

I will relate with pragmatism to Butler's and Benjamin's conflicting positions, since I regard the possible complexity of the third as being nearly impossible to extract from regular research interviews. A sociologist, in rare interview situations, may get narratives that seem to allow a complex understanding of the individual's desire, but I would suggest that one would need a therapeutic practice (or artistic expression) to come anyway near the unconscious aspects of the mediation of desire Aware of this and similar limitations in any sociological analysis of sexuality, I would argue, nevertheless, that 'sociological minds', wandering on the borders of their discipline can make important contributions to the understanding of sexuality.

Which are the constructions of desire that can be read out of my interviews with young people, with the outset in the understanding of desire accounted for above? How are the informants wording their negotiations of desire in specific situations? Before providing an attempted answer to these questions, a short description of the empirical material is necessary.

\section{Interviews}

The empirical material consists of five group interviews with Norwegian young adults, aged between 19 and 26 years. The size of the groups varies from two to five subjects. The first group was set up by an anonymous student, after I had announced in a lecture to around 200 students that I was looking for young people to take part in a sexuality study (Note 7). She contacted four female friends from a rural secondary school. I had mentioned that I would be particularly interested in young adults with homo-erotic experiences. This group consisted of five women, all of whom claimed a heterosexual identity, with homo erotic experience limited to one woman, who occasionally would kiss other young women at parties. To make sure that I would get a diverse material, I now specifically looked for people with other identities. The second group was established with the help of a young woman I met in a gay bar. She volunteered to put a group of lesbians together for me. The group of gay men was established in much the same way. I met a young man at the annual meeting for the local branch of the national gay and lesbian association, who arranged a meeting with some of his gay friends and acquaintances. A group of bisexual women was set up by a student who knew of the project. I made contact with the heterosexual young men through other contacts. The resulting group divisions were therefore formed with a simple and stereotypical understanding of sexual identity: five heterosexual women, two bisexual women, three heterosexual men, three lesbians and four homosexual men, 17 informants in all. This might seem paradoxical in a project on ambivalence, but not so much so if one thinks of identity as a notion that can contain a broad range of practices and psychoerotic states. What one person understands to be bisexual, might be seen as gay or straight by someone else, or others may find it difficult to categorise at all. I have not experienced this as a particular problem in the discussion, since the theoretical approach transgresses these categories. 
The interviews were designed to be about sexual experiences as well as the social milieu among young Norwegian adults. To better enable research question on a collective level, the interviews were conducted in groups. The questions that I will discuss in this paper were related to individual desire and its vicissitudes, and one could wish for additional individual interviews. Some of the stories were difficult to address in the desired level of detail, when other people were listening, which is visible in the analysis later in this text. I did one individual interview after a group interview, but unfortunately, time did not allow me to do more.

The heterosexual men I interviewed believed that they were not at all typical of heterosexual men of their age group, as they saw themselves as much more flexible and open than the average man, which may very well be the case. I do not need representative material to do the kind of analysis I offer here. However, it could have proved fruitful for the analysis and the discussion, if I had a larger material, more divers in terms of social background of the informants. That may have expanded the span of experiences and given the analytical approach a fuller scope.

The interviews were undertaken spring 2003 and summer 2005, three of them in rented meeting rooms, and two in the home of the researcher. When the interviews took place, all the interviewees had a relatively stable notion of themselves as being homo- hetero- or bisexual. However, it is possible to complicate the picture they draw of themselves by questioning the gendered character of the sexual encounters they describe during the interview. Here I will focus for the main part on two of the heterosexual men, and briefly on one of the homosexual women (Note 8). My conversation with the heterosexual young men took place in my home, including the first I look at here, the case of one of them, Ray. What happens when his girlfriend kisses another girl? What happens when he has sex with one of his best male friends? Who are the girls that he finds attractive and who are the men? Is his 'third' a shifting one? In short, how can we understand Ray as a desiring subject and object?

\section{One Man and the Third Elements}

When girls perform party-snogging with each other in secondary school, it is, he believed, to get attention from the boys. That is the general picture, according to Ray. The configuration of desire is then the following: the boy spectator is the subject and the two girls are together the object. The third element for the male spectator is understood, it seems, by both Ray and the researchers, to be the staged fantasy of 'female homosexuality'. None of the girls is seen as having a third element that eroticises the relation to the other girl. As an erotic relation, the theoretically possible one between the girls is in itself non-existent. The boy and the girls remain heterosexual, as they themselves also claim to be.

If we are to take the girls seriously as desiring subjects, as opposed to 'just' arousing the boys by running a performance of pornographic character, we'll at least have to ascribe the active desire of wanting to be the object in a heterosexual configuration. Let us suppose that at least one of them desires to be desired, by one of the boys (or girls) or by more than one boy (or girl), or perhaps she for her own sake desires to be watched by both boys and girls. There is an exhibitionist dimension and also a group dimension in this scenario of possibilities, since the performance takes place with a lot of people present and watching. She may have someone in particular on her mind, but if not, it will narrow down her number of possible sexual objects to those who are able to enjoy a scene between two girls. Now, that would ascribe sexual agency to the girls involved, at least in theory.

Ray was put out when his girlfriend kissed another girl at a party, especially when they were having a 'critical time' in their relationship. Ray puts it like this: 'I got a bit grumpy actually, I hadn't expected that'. This could be simply because he felt jealous since his girlfriend most likely did not do it to excite him - she was more likely on a different course because of the conflict between them. It would not have made it any better that a lot of his friends were watching their tensions and her choice to kiss someone else. But maybe more was at stake here? Ray said in the interview that it might be that 'real feelings' are evoked when girls are snogging at parties. Maybe this incident was the experience that made him say this, and that he in the situation had the sense that there was a certain excitement in the relation between the two girls. If so, his position as a sexual object (and subject) in relation to his girlfriend is threatened. It could be that his irritation is not caused by his girlfriend's show for other boys, but by a supposed desire that his girlfriend exercises, or risks, in her intimate contact with the other girl. He rejects being the subject for any of them and he rejects letting the homo-eroticism be the third element for himself. He and his girlfriend are having problems already, and what Ray needs least of all is a new third that possibly eroticises the kissing between his girlfriend and another girl. None of this is what he wants or needs. He is present but is in no way part of a desiring configuration. May be for Ray, direct participation, a feeling of concrete connectedness and particular communication has to be in some way part of the triangle? As shown below, in a sexual encounter with another man, Ray is playing an active role in staging the event and the direct and personal communication is central. This is what he says about an incident where he assisted a good friend who earlier on had told him that he was curious about having sex with a man: 
Ray: (interrupts) I tested it quite thoroughly. I have not been fucked in the ass, but I tested it with a mate (AB: in high school?) Yes. It was pretty extreme. I understand myself as very much a hetero and have never been particularly attracted to a boy or a man. But this was a good friend who was eager to try it. So, I went along.

AB: So it was driven by his wish and your curiosity?

Ray: Yes, I was curious and thought it might be cool. It was on his eighteenth birthday (laughter).

AB: What happened?

Ray: I pretended to fall asleep on a sofa at his place. When the others had left, I went to him and asked him if I could sleep in his bed. It was not previously agreed. He had just told me everything at a party once (Cato: he told you that..) That he liked me and wanted.. ok, I went up and lay down on his bed. We took a shower, messed (Norwegian: rote) everything except fucking in the ass. It was quite extreme. (AB: and both of you came?) No, not me. He had first priority. It was his 18th birthday! (laughter) We have not talked about it later, even if he is one of my best friends.

$\mathrm{AB}$ : Is he gay today?

Ray: No. (AB: but he wanted to go through with it..) Yes, he told me that he was gay, and had been in love with me for several years. He told me one time when he was drunk. I said that he had to test it and that I would do it with him. It happens often that you have to test things.

Ray presents his friend as the actively desiring subject and himself as object for him. Ray makes a plan, and set it into action so that his friend can have a sexual experience with a boy/man. There is nothing in Ray's story that might imply that the friend has a hold on him in any way, or that he feels that he has to be available for others who happen to desire him. Ray is a handsome young man, giving the impression of being confident and with considerable sexual experience. His stories were sometimes confirmed and expanded by one of the others in the group interview, when they rehearsed shared memories of the past. I suggest that Ray himself keeps a positive erotic image of what might happen if he seduces him, and that the friend's curiosity evokes Ray's interest as well. It would otherwise be difficult to make sense of Ray's actions in the situation with the birthday boy.

Ray is for the friend the specific object. The friend had even said he was in love with him (when he was drunk, it must be admitted). It is not important whether the friend actually said this. What is important is that Ray represents himself as special for the other man. Ray also speaks of himself as a general object, the representative of a Boy/Man for his friend. Ray acknowledges that the friend is in love with him, and at the same time chooses to overlook it. That way, he'll be able to be special for the other, be the general Other and not special really, and at the same time answer to his own curiosity about what sex with the birthday boy would be like. Ray becomes the sexual subject, perhaps one that desires the desire of the other. Ray actively let himself be objectified in this situation with another man, as I see it.

In the case with the kissing girls above, he would not let himself be subjectified or objectified. So, what exactly does Ray say about his attraction to women? I asked him what he first noticed with the woman he is with now.

Ray: The eyes. Yes, indeed, the eyes. Brown eyes, big eyes, I find it sexy with a bit of childlike radiance. Honest, open. Honest radiance.

AB: And what does a sexy man look like, a sexy boy?

(quiet for a long time)

Ray: More masculine than me, I know that.

If we agree that big, open eyes and childlikeness connotes the feminine, Ray's third element with his girlfriend, at least in the moment of introduction, is the feminine. An attractive man would be somewhat more masculine than himself. Ray is clear about his notion of boys and girls, and that he himself is a heterosexual man. He knows some things about himself with men in a sexual sense. Perhaps his desire for men first and foremost would be to be desired, and then a desire where his position as object for a more masculine man is made explicit (Note 9)? His desire for women would seem to represent the more conventional scenario, where he has a more clear position of being in control and positioned as a subject in his own conscious understanding of it. In both cases, Ray might also need the direct communication, person to person.

I have discussed Ray's desire by using the conventional gendered distinctions such as man-woman and feminine-masculine. A Lacanian might say that it is the phallus that sets the mark and makes Ray's desire possible at all. Jessica Benjamin might have said that Ray's desire is triangulated by the eroticity of communication, and that his individual process of subjectivation makes him invest both feminine and masculine to make contact and 
thereby make communication possible, that for Ray communication is 'the music' he attunes to. The problem with the Lacanian is obvious: we cannot escape the phallus. The problem with Benjamin is that she does not help us to understand why gender still is important in Ray's sexual attractions.

Robert is, like Ray, living with a female partner. When he was still in high school, he and two close male friends wanted to find out whether they 'liked...had something homosexual' in them. It all happened on a regular week day and without alcohol, which is important, since other possibly homoerotic experience such as kissing, that this group of young men told me about, was connected to party situations and drinking. Robert talks of it as an unromantic and an un-desiring event: 'We had an evening to find out about this'. It being successful or not depends on the eyes of the beholder, but Robert explains that they were not quite able to relax.

Robert: It got a bit twisted after a while. We weren't able to loosen up enough, or perhaps we didn't get aroused enough to perform male to male intercourse, and suddenly it all became very difficult. But then one of the guys provided us with a naked women on a computer screen (laughter).

The naked women might be seen as the final proof, the litmus test of his heterosexual substance, but this could be queried further: how do the individual young man in this collective masturbatory situation relate to the porn image and to each other? What is the third element for each of them? Does the fact that this is a group of men mean something for any of them or is the erotic dynamic exclusively a matter of individual fantasies, come to life by the image? Is the desire necessarily heterosexual for each of them? Whatever the answer to such questions, Robert was willing to explore sex with men when he was younger, and will sometimes also today consider invitations from men. Maybe the man has to be exclusively special? On one occasion he attended a rock festival in The Netherlands, and late into the night he happened to find himself sitting next to a famous musician. The artist was well known for his bisexuality, and he and Robert soon started to kiss intimately. Robert was given the opportunity to leave the party and have sex with him, but other things happened and the sexual encounter that might have happened was called off.

Robert: He said that he thought that I was 'fine' and right then I could have left with him, but the moment slipped by.

AB: What do you think made you ready to go with him?

Robert: I suppose that I wanted to check it out, plus he was a rock star.

\section{AB: Status?}

Robert: A bit of that, plus it would have been a story to tell later (laughter). It's probably a large part about that.

Robert does not directly address sexual attraction here, and unfortunately I don't ask. Robert comes across also elsewhere in the interview as one who is willing to take risks, and let lust and pleasure unfold. Let us assume that Robert kissed the musician because Robert liked it, and that he might have left with him because there was a desire to pursue this further; he experienced something sexually pleasurable that he wanted to find out more about. What we then know about the attraction is that it is connected to the other man's status. Robert obviously seems to believe that in making an impression in his social environment, a story about sex with the artist would add to his own position. Robert's sexual object holds a position above him in the social hierarchy. What can we say about the third element here? Is hierarchical difference that which eroticises the object for Robert? What, in that case, is it that makes it different from heterosexual, or phallic eroticity, associated with masculinity, here put into play between men? The answer is not straight forward. It might be that the utterance 'he said that he thought I was "fine"" implies that Robert is conscious of his own status as an object for the sexual desire of the other man, and also conscious of his own desire for the other one's desire. As with Ray, to the extent that he is curious about sexual experience with other men, it might be that the appeal is in the prosperity to be in the object position. Is it also like that for him with women? Let us hear what he says about having a female partner.

I asked the heterosexual men about 'gentleman's sex', that is, if they sometimes would feel that they are too considerate, and responsible for their partner. All three wanted to have the word, and Robert won.

Robert: I'm so much a guy who can easily forget about myself, and I believe many of us are, in this way, kind of 'good boys'. There are so many different ways to have sex. (..) So if we are having regular sex, it can easily end with a joint form of mutual masturbation, or what to call it. If I feel that I start to come, I'll cool down and wait for her to come first. Not a long time ago she said to me: 'why don't we fuck and you think only of yourself?' That was great fun! She was aroused by me not bothering about her. I usually like to be in a certain control of my own body, but it is also fun not to be.

AB: Perhaps she felt that there was too much expected of her? 
Robert: Yes, right, and that she felt that it wasn't so good for me

\section{AB: And you, did you manage on your first try?}

Robert: Yes, we are good at using our fantasy, so we take on a lot of fun roles. I think it's important to create an unprejudiced zone: 'Even if I like you to be like this to me right now, it does not mean that I dream that a ... you know.. turns up', but it went well, the sexual zone is a creative zone.

AB: so you can play on you going out of the role of the gentleman in sex, and..

Robert: Yes, now and then, but I'm quite sure that she's pleased that we work together and that I stretch a bit further than achieving the wanking-speed to get off.

There are alternative approaches towards an interpretation of this, and I shall try to stay focused on desire. It seems like Robert is more concerned about controlling himself than controlling his girlfriend. The marking of erotic difference between him and her is not embedded in his control over her, as I hear him. His presentation of this indicates that both of them, and she in particular, find it arousing that he takes control in the sense of putting himself in the centre of events. He underlines that imbalance in the sexual occurs only occasionally and is suggested by her and that she basically is pleased that he makes some efforts to satisfy her. Robert's problem with the good-boy-mode is actually not his. It is his girlfriend who now and again will think it's a bit too much of a good thing and suggests that he takes on a more self-centred role. Robert is a bit vague in representing images of his female object, but in this description it is she who establishes herself as object in his control. One way of seeing this is that she, at least occasionally, wants him to, in an open and direct way, show her that she is imagined to be his object.

From the particular situation he describes above, it seems that Robert tend to see himself as object both with men and women, and that this is part of the structure of his sexual desire, this is in contrast to Ray, who expressed more of a different 'third' relating to persons of the two sexes. Robert says at another moment in the interview that 'She sometimes looks very childlike, and some times very much a woman, and it presses both buttons with me'. Ray had just used the word 'childlike', thereby introducing that as a concept in the conversation, making it simple for Robert to pick it up and perhaps use it with a different meaning. I should have asked Robert what he meant by it, but did not. I also should have asked Robert what he meant by 'very much a woman', but again I did not. A woman that is very much a woman is not just any woman, and she cannot be the woman that his girlfriend 'really' is. Is it a symbolically motherly woman he is alluding to where his position could be imagined as obedient and a good boy? Or is it perhaps more of femme fatale he has on his mind? Or, is it the ultimate feminist woman, whom he imagines never stops requiring his services? In all cases, he would be the one doing his best to satisfy the female partner, and one could suggest that the third is 'imaging the object position' or as likely, if we could have taken a closer look at this, the third would be the fact that Robert in all this cases would be in control of the woman's pleasure - The Master of Pleasing.

Robert has his mind set on the creative aspect of sex, and more so than the other two in this interview. He narrated a story about fantastic sex, where sex organs had not been involved, without orgasms, and where sex had been a 'continuous state' and first of all about giving oneself, which means sex as something that cannot very easily be put into words with references to gendered terms. Robert seems capable of going in and out of subject- and object-positions, and also to enjoy sexual exchange where the distinction between subject and object is partly resolved. In other words, he seems apt to follow the advice from sexologists and feminists to allow himself to be objectified. The sex advisors claim that, in return, sex life could become varied and exciting, and we can agree or not to that. The question, however, is not only whether men will allow women to objectify them and to take pleasure in that. Equally challenging is whether the female partner finds it in her to enjoy a constellation where the man is an object for her. These questions are basically about the reworking of dominant psychological and symbolic configurations, intertwined in the experience of pleasure for both partners. I will now proceed to the brief discussion of Eva's sexual desires, as I've interpreted them from the group interviews. Eva presents herself as lesbian, and again I am asking if there is more to be said about her desire than simply that it is homosexual.

\section{The Anabolic Almost Mr. Right}

Eva has recognised desire in relation to women, and she says that she primarily wants to be with women. She has had one long-term relationship with a man, and in many ways that was a good relationship. He is today her best 'mate'. She says that probably she too will meet 'Mr. Right', but that it has up till now always turned out that something is not right after all. Most likely she'll continue to date women. She has a female domestic partner. Eva was out on the town with her sister the first time she met her present partner. Eva had seen her before, and perhaps also played billiards with her, but did not know her. At one point late into the night, Eva, her sister and the new 
acquaintance began playing with a pair of mittens. They would have them on by turns and performed a kind of theatre, and in the end they laughed so hard that they all ended up on the floor.

AB: Did you fall in love with her then?

Eva: No, not then, but I was very, very fascinated. You cannot play with everyone like that, and when you can, it implies that you are online with the person too. And that we all could be there, on the floor, laughing, having fun with a pair of mittens!

It was only later that Eva actually fell in love, and the joint playfulness was important to Eva. Asked about her attraction for the man she used to have a relationship with, the answer comes prompt:

Eva: The Body. Yes, that was the decisive.

$\mathrm{AB}$ : Athletic?

Eva: A 'boler' (Norwegian slang). I found that out later.

$\mathrm{AB}$ : What is a 'boler'?

Eva: One who pumps iron and eats anabolic steroids.

As in the case of Ray it seems that the erotic has different meanings for Eva, depending on whether it is a man or a woman who is the object of her desire. The last time Eva and her partner has sex, Eva was the one who initiated it. Her partner came over to her and corrected her slanting ear ring. It was something with the touch when her partner did this, and also that she actually came over to do it - the situation itself, that Eva felt taken care of and attended to. She can desire an extraordinary muscular man, but at the moment it seems that the promises of communication and playfulness with a woman work as more of a third element for Eva.

\section{So what?}

In this analysis of relations of desire, I have listened to what three of the informants have to say about themselves, and I have used the terms hetero and homo to describe their experiences. However, I have not felt obliged to keep them in the category they say that they belong to, nor to find another category that I think would suit them better. On the contrary, I have tried to maintain an analytical grip that makes the categories less important for my reading of the interviews. That does not make the sexual identity categories less important for my informants, of course. I presume that the sexual identity categories are crucial for most people, as a way of belonging and positioning oneself within one's culture. However, by applying a notion of a 'third element' as that which eroticizes, I have tried to query how we usually understand desire as either heterosexual or homosexual. Gender difference eroticizes in complex ways and sexual attraction is obviously more than the one between a masculine man and a feminine woman. Let's take Robert as an example.

When sexually involved with a woman, Robert is more than willing to do what she wants him to do. In a scene when he is asked only to think of pleasuring himself, he formulates a letting go of any 'control of my own body' and not in terms of his control of her. He also talks about his willingness to go with a man who is known to be bisexual, a man with considerably more status than himself. In un-gendered terms we can say that Robert's desire is, at least in some situations, about being subservient and giving, regardless of the gender of the sexual partner. Robert is also active, initiating and transgressive when together with his female partner, as she is with him. The two of them are taking and giving in the same sort of gendered ways, which means that we can read that particular erotic constellation in a symbolic sense as homo-erotic. The homosexual has a place within that which from the outside looks like the straightest relation.

Also, it is not necessarily gender difference that eroticises, or at least, from what my informants are saying, it is not always possible to see gender difference as central to the erotisation of a relation. When Eva is attracted to a muscular man, the all too obvious triangle is man, woman, masculinity. The erotic relation is heterosexual, biologically (the bodies that meet) and symbolically (the signs for the erotic). Together with a woman, erotisization happens differently for Eva and the language of gender and gender difference seems less appropriate. What counts is to play, to be touched, to be cared for - that is, in the erotic meeting between Eva and her present female partner, the third element is not necessarily gendered, or gendered in any obvious way. And if we are to talk about Eva's present sexual relation in gendered terms, we could say that Eva's desire is to be on the receiving end of a woman's care. In standard heterosexual terms, she has then to some extent slid into the stereotypical man's position. The erotic dynamic is still heterosexual, but now with Eva in the masculine position in the symbolic erotic.

The 'so what?' in the headline of this chapter, is of course debateable, but I would hope that this analysis contributes to an increased awareness of how we name sexual practices, both within social science and also sexual 
politics. When we put on theoretical spectacles that allow us to see the space opened up by the eroticising third, homosexuality can be seen as an active element in relations between heterosexually self identified individuals, while heterosexuality can be seen as an active element between homosexuals. The vicissitudes of individual and collective erotic fantasies involved in the third should make us alert to any claim of being $100 \%$ straight or gay, and in particular, it should make us able to reply 'who is speaking?', when a righteous mix of religious leaders and other culturally conservatives want to deny gays and lesbians legal rights. The social and political implications of such an understanding of erotic desire could be profound was it to become widely spread. Not only would traditional gay and lesbian politics, be questioned (Bolsø, 2008). Even more important: 'the heterosexual' and the 'heterosexually erotic' would clearly become more complicated, and sociologists studying politics, management and working-places, just to suggest some concrete empirical areas, would have to include the possibility of forms of eroticised power that today gets too little, if any attention at all.

I have not used any notion of 'the unconscious' analytically in this article. It is a concept which, I must admit, seems a little too intimidating for sociological investigation. Rather, I have conceptualized the interface between the social and, for the sociologist, accessible representations of the symbolic erotic. However, although its further elaboration will have to await another time, while I was closing this article, I encountered two British psychoanalytically erudite researchers involved in 'psychosocial studies', who hint at a deconstruction of the unconscious in a way that implies a very interesting space for sociology within sexuality studies:

'(..) psychological and social, inner and outer, are only artificially separated, and are constituted by something else that runs through them, sometimes emerging in surprising ways that psychoanalysts code as the "unconscious" in its signifying, "non-sensical" materialization' (Frosh and Baraitser 2008).

\section{References}

Benjamin, J. (1998). The Shadow of the Other: Intersubjectivity and Gender in Psychoanalysis. New York: Routledge.

Blumer, H. (1969). Symbolic Interactionism: Perspective and Method. Berkley: University of California Press.

Bolsø, A. (2007). Deg, meg og det tredje - triangulering av begjær. In A. Annfelt, B. Andersen \& A. Bolsø (Eds). Nar heteroseksualiteten ma forklare seg. Trondheim, Tapir Akademisk Forlag.

Bolsø, A. (2008). Mission Accomplished? Gay Elitism and the Constant Misery of a Minority. Trikster : Nordic Queer Journal. [Online] Available: http://trikster.net/1/bolsoe/1.html

Butler, J. (1993). Bodies That Matter: on the Discursive Limits of Sex. London: Routledge.

Butler, J. (2000). Longing for Recognition: Commentary on the Work of Jessica Benjamin. Studies in Gender and Sexuality, 1(3), 271-290. http://dx.doi.org/10.1080/15240650109349159

Butler, J. (2004). Undoing Gender. New York, London: Routledge.

Chodorow, N. J. (1994). Femininities, Masculinities, Sexualities. Freud and beyond. Lexington. Kentucky: The University Press of Kentucky.

Chodorow, Nancy J. (1989) Feminism and psychoanalytic theory. New Haven, Conn.: Yale University Press.

Epstein, S. (1996). A Queer Encounter: Sociology and the Study of Sexuality. In S. Seidman (Ed.) Queer Theory/Sociology. Cambridge MA, Oxford: Blackwell Publishers.

Epstein. S. (1991). Sexuality and identity: The contribution of object relations theory to a constructionist sociology. Theory and Society, 20, 825-873. http://dx.doi.org/10.1007/BF00678098

Freud, S. (1977). On Sexuality. Three Essays on the Theory of Sexuality and Other Works. London: Penguin Books.

Frosh, S. \& Baraitser, L. (2008). Psychoanalysis and Psychosocial Studies. Psychoanalysis. Culture and Society, 13, 346-365.

Green, A. I. (2008). Erotic habitus: toward a sociology of desire. Theory and Society, 37, 597-626. http://dx.doi.or $\mathrm{g} / 10.1007 / \mathrm{s} 11186-007-9059-4$

Ho, P. S. Y. \& Tsang, A. K. T (2000). Negotiating Anal Intercourse in Inter-Racial Gay Relationships in Hong Kong. Sexualitites, 3(3), 299-323. http://dx.doi.org/10.1177/136346000003003002

Laumann, E. O. \& Gagnon, J. H. (1995). A sociological perspective on sexual action. In R.G. Parker and J. Gagnon (Eds). Conceiving Sexuality: Approaches to sex research in a postmodern world. New York, London: Routledge. 
Lauretis, T. (1994). The Practice of Love. Lesbian Sexuality and Perverse Desire. Bloomington: Indiana UP.

McIntosh, M. (1968). The homosexual role. Social Problems, 16(2), 129-143. http://dx.doi.org/10.1525/sp.19 68.16.2.03a00050

Mead, G.H. (2005) (1934). Sindet, selvet og samfundet. København: Akademisk forlag. Mind, Self, and Society. Chicago: University of Chicago Press.

Middelthon, A. L. (2002). Being Anally Penetrated: Erotic Inhibitions, Improvizations and Transformations. Sexualities, 15(2), 181-200. http://dx.doi.org/10.1177/1363460702005002003

Schramm-Evans, Z. (1995). Making Out. The Book of Lesbian Sex and Sexuality. London, San Fransisco: Pandora.

Segal, L. (1994). Straight Sex. The Politics of Pleasure. London: Virago Press.

Seidman, S. (Ed.) (1996). Queer Theory/Sociology. Cambridge MA, Oxford: Blackwell Publishers.

Simon, W. \& Gagnon, J. H. (1986). Sexual scripts: Permanence and change. Archives of Sexual Behavior. 15, 97-120. http://dx.doi.org/10.1007/BF01542219

Smith, P. (2001). Cultrual Theory. An Introduction. In the series $21^{\text {st }}$ Century Sociology. Oxford: Blackwell Publishers.

The International Association of Sociology. [Online] Available: http://www.isa-sociology.org/

Weeks, J. \& Plummer, K. (1981). Postscript: 'The homosexual role' revisited. Jeffrey Weeks and Kenneth Plummer interview Mary McIntosh. In K. Plummer (Ed.). The Making of the Modern Homosexual. Totowa, New Jersey: Barnes and Noble Books.

Whittier, D. K. \& Melendez, R. M. (2004). Intersubjectivity in the intrapsychic sexual scripting of gay men. Culture, Health and Sexuality. 6(2), 131-143. http://dx.doi.org/10.1080/13691050310001607250

\section{Notes}

Note 1. 'Sexual desire' and 'erotic desire' will be used interchangeable in this text, even if I understand the former to be the most inclusive term and the latter tendentiously more linked to a conscious and actual erotic situation.

Note 2. The actual chronology of this is of course less clear, since the book is based on lectures she presented in April 1990 (Blazer lectures, University of Kentucky).

Note 3. For further reading on symbolic interactionism see Blumer 1969, Smith 2001.

Note 4. I would not agree though, that Foucault is not also a social scientist.

Note 5. George Herbert Mead was influenced by Georg Wilhelm Friedrich Hegel and might have got from him the inspiration to theorize the role of the other in the development of selfhood [1934]. However, there are no references to the philosopher in my Danish translation of Mead's standard work on selfhood and society (2005).

Note 6. This way of thinking desire beyond the Lacanian Law of the Father, is different from the one taken in her book Bodies That Matter, where she breaks up the sexual binary in a critique of the Lacanian symbolic.

Note 7. 'When heterosexuality has to explain itself', Program for gender research, The Research Council of Norway.

Note 8. A reader mastering the Norwegian language will find discussions of other informants too (Bolsø 2007).

Note 9 . There is obviously for Ray a limit set by penetrative, anal sex with a man, which is indeed a contested area within (gay) male sex (Middelthon 2002, Ho and Tsang 2000). 